\title{
Optimization of Heavy Vehicle Suspension System Using Composites
}

\author{
K. Viswanatham, H. Raghavendra Rao \\ 1 (Mechanical Engineerig, G.Pulla Reddy Engineerig College (Autonomous) IJ Ntu Anantapur, India) \\ 2 (Mechanical Engineerig, G.Pulla Reddy Engineerig College (Autonomous) IJ Ntu Anantapur, India)
}

\begin{abstract}
A leaf spring is a simple form of spring, commonly used for the suspension in wheeled vehicles. Leaf Springs are long and narrow plates attached to the frame of a trailer that rest above or below the trailer's axle. There are mono leaf springs, or single-leaf springs, that consist of simply one plate of spring steel. These are usually thick in the middle and taper out toward the end, and they don't typically offer too much strength and suspension for towed vehicles. Drivers looking to tow heavier loads typically use multi leaf springs, which consist of several leaf springs of varying length stacked on top of each other. The shorter the leaf spring, the closer to the bottom it will be, giving it the same semielliptical shape a single leaf spring gets from being thicker in the middle. The automobile industry has shown increased interest in the replacement of steel spring with fiberglass composite leaf spring due to high strength to weight ratio. In this thesis a leaf spring used in a heavy vehicle is designed. While designing leaf spring following four cases are considered: by changing the thickness, changing no. of leaves, changing camber and changing span. Present used material for leaf spring is Mild Steel. The objective of this thesis is to compare the load carrying capacity, stiffness and weight savings of composite leaf spring with that of steel leaf spring. The design constraints are stresses and deflections. In this thesis, the material is replaced with composites since they are less dense than steel and have good strength. The strength validation is done using FEA software ANSYS by structural analysis. Modal analysis is also done to determine the frequencies. Analysis is done by layer stacking method for composites by changing number of layers 3, 5, 11 and 23. The composites used are Aramid Fiber and Glass Fiber.
\end{abstract}

Keywords: Composite materials, design constrain, leaf spring, material property, and analysis.

\section{Introduction}

Suspension is the term given to the system of springs, shock absorbers and linkages that connects a vehicle to its wheels. Suspension systems serve a dual purpose - contributing to the car's road holding/handling and braking for good active safety and driving pleasure, and keeping vehicle occupants comfortable and reasonably well isolated from road noise, bumps, and vibrations, etc. These goals are generally at odds, so the tuning of suspensions involves finding the right compromise. It is important for the suspension to keep the road wheel in contact with the road surface as much as possible, because all the forces acting on the vehicle do so through the contact patches of the tires. The suspension also protects the vehicle itself and any cargo or luggage from damage and wear. The design of front and rear suspension of a car may be different.

\section{Introduction To Aramid Fiber And Glass Fiber}

Aramid fibers are a class of heat-resistant and strong synthetic fibers. They are used in aerospace and military applications, for ballistic rated body armor fabric and ballistic composites, in bicycle tires, and as an asbestos substitute. The name is a portmanteau of "aromatic polyamide". They are fibers in which the chain molecules are highly oriented along the fiber axis, so the strength of the chemical bond can be exploited. Aramid fiber characteristics Aramids share a high degree of orientation with other fibers such as ultrahigh molecular weight polyethylene, a characteristic that dominates their properties. Glass fiber (also spelled glass fiber) is a material consisting of numerous extremely fine fibers of glass. Glassmakers throughout history have experimented with glass fibers, but mass manufacture of glass fiber was only made possible with the invention of finer machine tooling. In 1893, Edward Drummond Libby exhibited a dress at the World's Columbian Exposition incorporating glass fibers with the diameter and texture of silk fibers. This was first worn by the popular stage actress of the time Georgia Cay van. Glass fibers can also occur naturally, as Pele's hair. Glass wool, which is commonly known as "fiberglass" today, however, was invented in 1938 by Russell Games Slayer of Owens-Corning as a material to be used as insulation. It is marketed under the trade name Fiberglas, which has become a genelricized trademark. Glass fiber is commonly used as an insulating material. It is also used as a reinforcing agent for many polymer products; to form a very strong and light fiber-reinforced polymer (FRP) composite material called glass-reinforced plastic (GRP), popularly known as "fiberglass". Glass fiber has roughly comparable properties to other fibers such as polymers and carbon fiber. Although not as strong or as rigid as carbon fiber, it is much cheaper and significantly less brittle. 


\subsection{ARAMID FIBER PROPERTIES}

Physical Properties

Density

Mechanical Properties

Tensile Strength, Ultimate

Modulus of Elasticity

Poisson's Ratio

Thermal Properties

Melting Point

Maximum Service Temperature

Air,
Metric

$1.47 \mathrm{~g} / \mathrm{cc}$

Metric

$3450 \mathrm{MPa}$

$179 \mathrm{GPa}$

0.36

Metric

$\underline{500}{ }^{\circ} \mathrm{C}$

$425{ }^{\circ} \mathrm{C}$

\section{Literature Survey}

3.1 Ballinger C.A. - Getting Composites into Construction, Reinforced Plastics, 1995. Composite leaf spring in the early 60 failed to yield the production facility because of inconsistent fatigue performance and absence of strong need for mass reduction. Researches in the area of automobile components have been receiving considerable attention now. Particularly the automobile manufacturers and parts makers have been attempting to reduce the weight of the vehicles in recent years. Emphasis of vehicles weight reduction in 1978 justified taking a new look at composite springs. Studies are made to demonstrate viability and potential of FRP in automotive structural application. The development of a lit flex suspension leaf spring is first achieved. Based on consideration of chipping resistance base part resistance and fatigue resistance, a carbon glass fiber hybrid laminated spring is constructed. A general discussion on analysis and design of constant width, variable thickness, and composite leaf spring is presented. The fundamental characteristics of the double tapered FRP beam are evaluated for leaf spring application. Recent developments have been achieved in the field of materials improvement and quality assured for composite leaf springs based on microstructure mechanism. All these literature report that the cost of composite; leaf spring is higher than that of steel leaf spring. Hence an attempt has been made to fabricate the composite leaf spring with the same cost as that of steel leaf spring.

\section{Mathematical Analysis}

This chapter involves the determination of bending stress by using mathematical formula. Determination of length of leaf spring leaves, consequently the rotation angle and the radius of curvatures of each leaf, these are used in geometric modeling.

\subsection{Length Of Leaf Spring Leaves}

The length of the leave spring leaves obtained as discussed below Let

$$
\begin{aligned}
& 2 \mathrm{~L}_{\mathrm{I}}=\text { Length of span or overall length of the spring } \\
& \text { I = Distance between centers of U- Bolts } \\
& \text { It is the ineffective length (I.L) of the leaf spring } \\
& \mathrm{n}_{\mathrm{F}}=\text { Number of full length leaves } \\
& \mathrm{n}_{\mathrm{G}}=\text { Number of graduated leaves and } \\
& \mathrm{n}=\text { Total number of leaves }=\mathrm{n}_{\mathrm{F}}+\mathrm{n}_{\mathrm{G}} \\
& \text { E.L }=\text { Effective length of the spring }=2 \mathrm{~L}_{\mathrm{I}}-(2 / 3) \mathrm{I}
\end{aligned}
$$

Length of smallest leaf $=\quad \frac{\text { Effective length }}{n-1} \quad X$ 1+ Ineffective length


Length of next leaf $=$

Similarly,

Length of $(n-1)^{\text {Th }}$ Leaf $=$
Effective length

$$
\mathrm{X} 2+\text { Ineffective length }
$$
$\mathrm{n}-1$

\section{Effective length}

$\mathrm{n}-1$

Length of master leaf $=2 L_{I}+2 \pi(d+t)$

Where

$\mathrm{d}=$ Inside diameter of eye

$\mathrm{t}=$ Thickness of master leaf

Relation between radius of curvature $(\mathrm{R})$ and the camber $(\mathrm{C})$ of the spring

\subsection{Geometric Properties Of Leaf Spring}

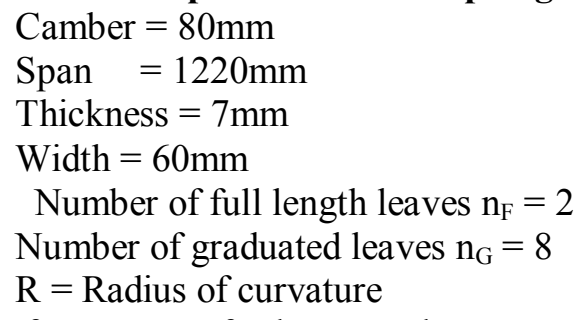

Radius of curvature of subsequent leaves $=$ Preceding Radius of curvature + Thickness

The lengths, radius of curvatures, rotation angles are calculated in different cases

Case I - Thickness is the variable

Case 2- Camber is the variable

Case 3 - Span is variable

Case 4 - Number of leaves is the variable

CASE 1 - When thickness of leaves changes from $7 \mathrm{~mm}$ to $10 \mathrm{~mm}$ with the interval of $1 \mathrm{~mm}$, the lengths, radius of curvatures, rotation angles are calculated.

In case I, the thickness only varies, the remaining geometric properties are common

Case 1 (a): Thickness of leaves $=7 \mathrm{~mm}$

$80 \mathrm{~mm}$

The below geometric properties are common to case 1 (b) case 1 (c) Case 1 (d) camber $=$

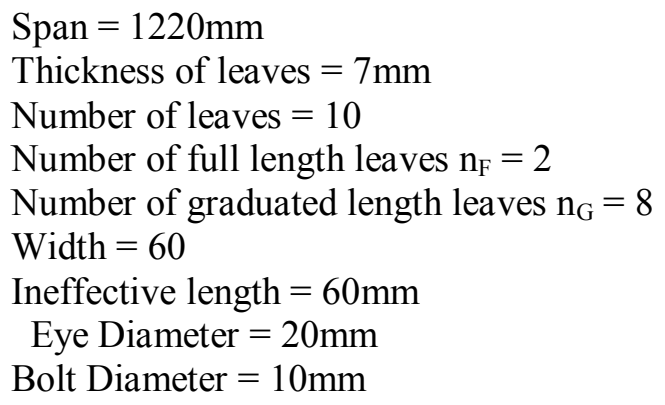




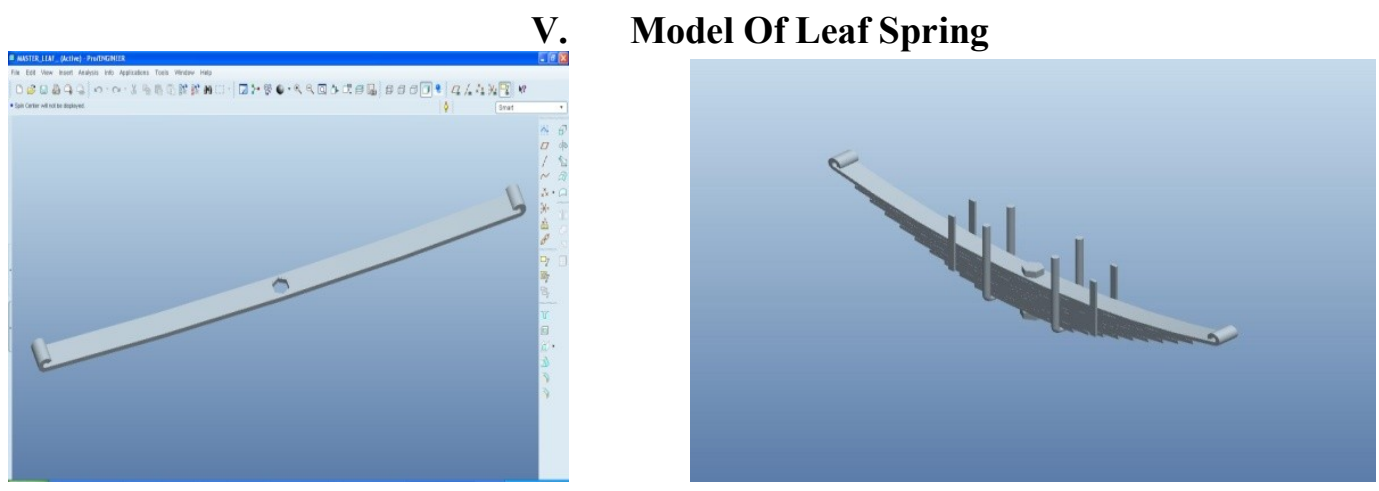

5.1 Structural And Frequency Analysis Of Leaf Spring

\subsection{Mild Steel}

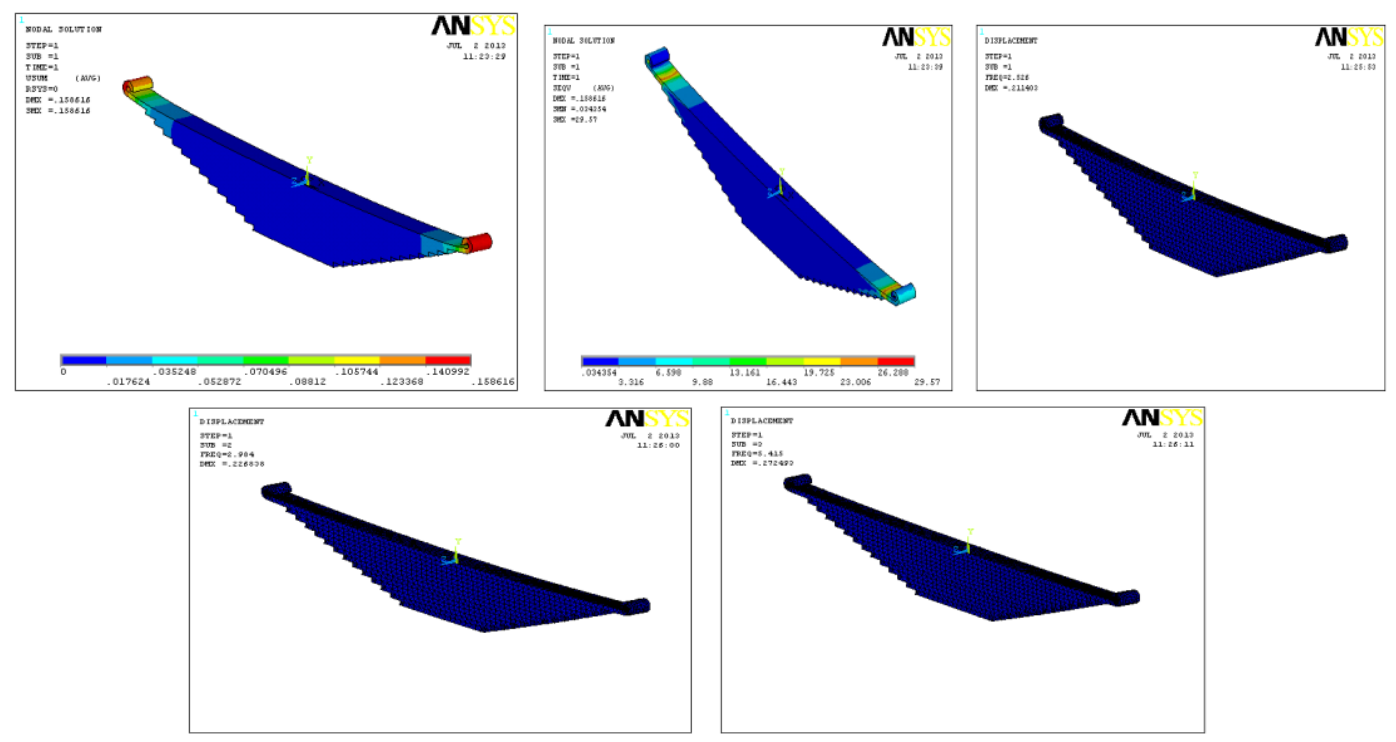

\subsection{Aramid Fiber}

Material Properties: Young's Modulus (EX) : 179000N/mm²

Poisson's Ratio (PRXY): 0.36

Density $\quad: 0.00000147 \mathrm{~kg} / \mathrm{mm}^{3}$

Displacement Vector Sum
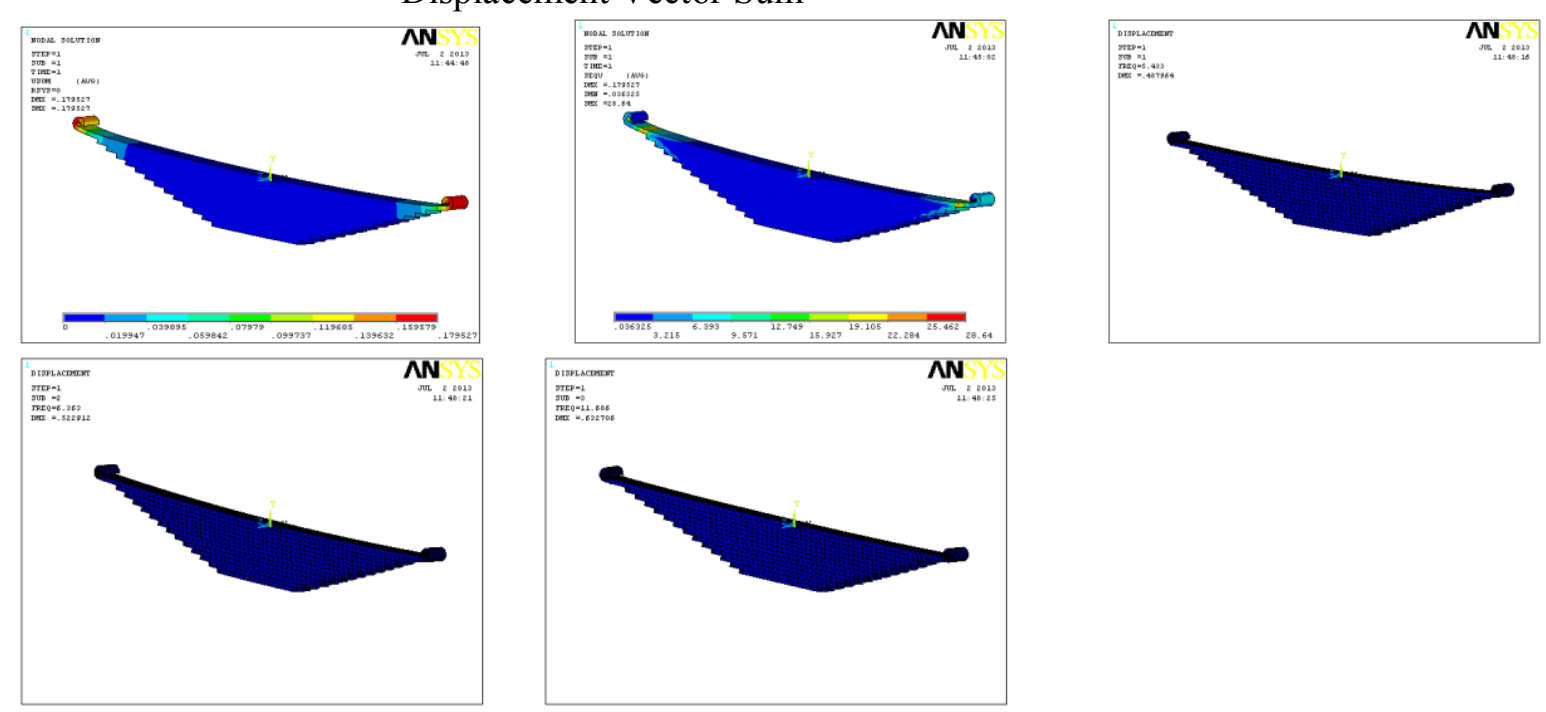
5.4 Glass Fiber

Material Properties: Young's Modulus (EX): 85500/mm²

$$
\begin{array}{ll}
\text { Poisson's Ratio (PRXY) } & : 0.2 \\
\text { Density } & : 0.00000254 \mathrm{~kg} / \mathrm{mm}^{3}
\end{array}
$$

Displacement Vector Sum

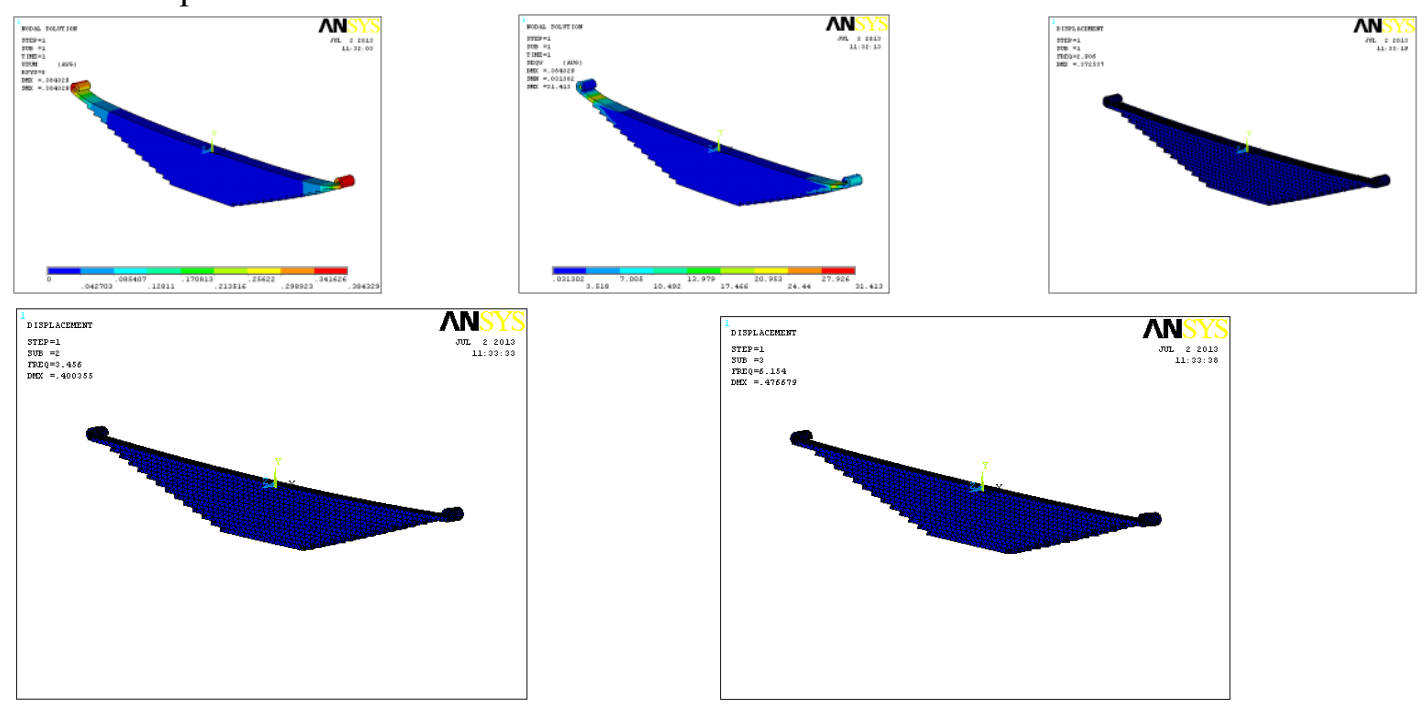

VI. structural and frequency analysis of main leaf using layer stacking method 6.1 11-Layers

\subsection{Mild Steel}
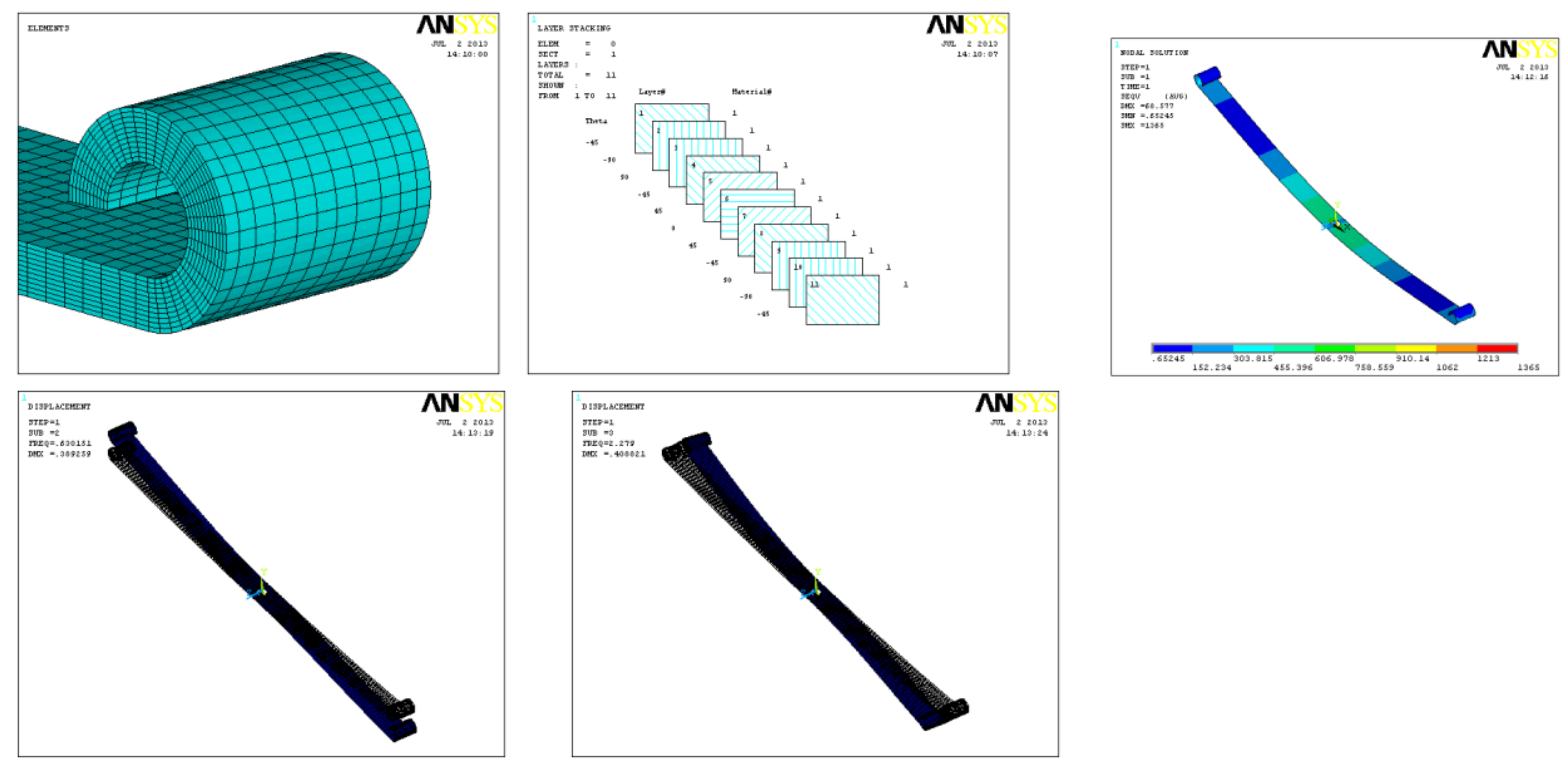

6.3 Aramid Fiber
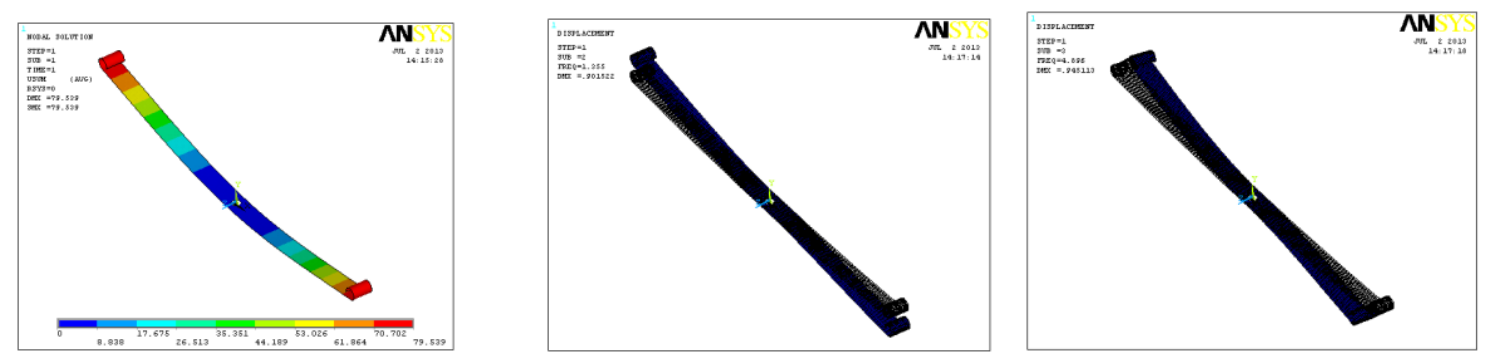


\subsection{GLASS FIBER}
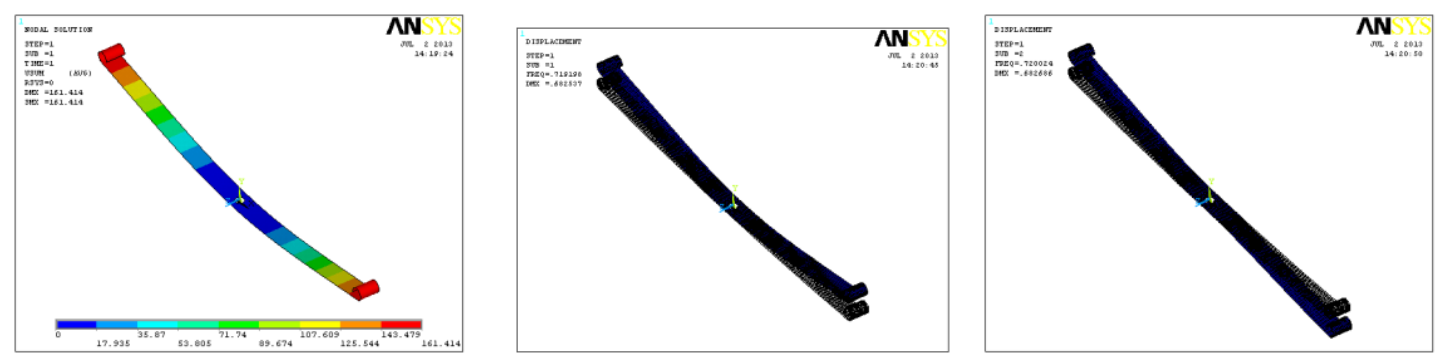

VII. Results And Discussions Weight Comparison

\begin{tabular}{|c|c|}
\hline & WEIGHT (Kg) \\
\hline MILD STEEL & 138.217 \\
\hline ARAMID FIBER & 25.882 \\
\hline GLASS FIBER & 44.722 \\
\hline
\end{tabular}

7.1 Without Layers Structural Analysis

\begin{tabular}{|c|c|c|c|}
\hline & STEEL & $\begin{array}{c}\text { ARAMID } \\
\text { FIBER }\end{array}$ & $\begin{array}{c}\text { GLASS } \\
\text { FIBER }\end{array}$ \\
\hline $\begin{array}{c}\text { DISPLACEMENT } \\
(\mathbf{m m})\end{array}$ & 0.158616 & 0.179527 & 0.384329 \\
\hline STRESS (N/mm ${ }^{2}$ ) & 29.57 & 28.64 & 31.413 \\
\hline $\begin{array}{c}\text { ALLOWABLE } \\
\text { STRESS (N/mm }\end{array}$ & 1600 & 3450 & 4135 \\
\hline
\end{tabular}

7.2 Modal Analysis

\begin{tabular}{|c|c|c|c|c|}
\hline \multicolumn{2}{|c|}{} & STEEL & ARAMID FIBER & GLASS FIBER \\
\hline \multirow{2}{*}{ MODE1 } & Hz & 2.528 & 5.433 & 2.905 \\
\cline { 2 - 5 } & Deflection $(\mathbf{m m})$ & 0.211403 & 0.487964 & 0.372537 \\
\hline \multirow{2}{*}{ MODE 2 } & Hz & 2.948 & 6.363 & 3.456 \\
\cline { 2 - 5 } & Deflection (mm) & 0.226838 & 0.522912 & 0.400355 \\
\hline \multirow{2}{*}{ MODE 3 } & Hz & 5.415 & 11.686 & 6.154 \\
\cline { 2 - 5 } & Deflection $(\mathbf{m m})$ & 0.272493 & 0.632706 & 0.476679 \\
\hline
\end{tabular}

\subsection{1-Layers Structural Analysis}

\begin{tabular}{|c|c|c|c|}
\hline & STEEL & ARAMID FIBER & GLASS FIBER \\
\hline $\begin{array}{c}\text { DISPLACEMENT } \\
(\mathrm{mm})\end{array}$ & 68.577 & 79.539 & 161.414 \\
\hline STRESS $\left(\mathbf{N} / \mathbf{m m}^{2}\right)$ & 1365 & 1368 & 1371 \\
\hline $\begin{array}{c}\text { ALLOWABLE } \\
\text { STRESS (N/mm²) }\end{array}$ & 1600 & 3450 & 4135 \\
\hline
\end{tabular}

\subsection{MODAL ANALYSIS}

\begin{tabular}{|c|c|c|c|c|}
\hline \multicolumn{2}{|c|}{} & STEEL & ARAMID FIBER & GLASS FIBER \\
\hline \multirow{2}{*}{ MODE1 } & Hz & 0.628954 & 4.896 & 0.719198 \\
\cline { 2 - 5 } & Deflection (mm) & 0.389108 & 0.945113 & 0.682537 \\
\hline \multirow{2}{*}{ MODE 2 } & $\mathbf{H z}$ & 0.630151 & 1.355 & 0.720024 \\
\cline { 2 - 5 } & Deflection (mm) & 0.389259 & 0.901522 & 0.682686 \\
\multirow{2}{*}{ MODE 3 } & $\mathbf{H z}$ & 2.279 & 1.352 & 2.606 \\
\cline { 2 - 5 } & Deflection (mm) & 0.408821 & 0.901045 & 0.71835 \\
\hline
\end{tabular}

\section{Conclusion}

In this thesis, a leaf spring is designed for Ashok Leyland Viking heavy vehicle. The data is collected from net for the specifications of the model. The leaf spring is designed for the load of $14087.5 \mathrm{~N}$. Theoretical calculations have been calculated for leaf spring dimensions at different cases like varying thickness, camber, span and no. of leaves by mathematical approach. In this thesis, analysis has been done by taking materials Mild Steel, Aramid Fiber and Glass Fiber. Structural and modal analysis are conducted on total assembly of leaf spring and for single leaf by using layer stacking analysis, this analysis is done for only composites. The results show: The stresses in the composite leaf spring of design are much lower than that of the allowable stress. The strength to weight ratio is higher for composite leaf spring than conventional steel spring with similar design. 
Weight of the composite spring by using Aramid Fiber is reduced by $112 \mathrm{Kgs}$ than by using steel, by using material Glass Fiber it is reduced by $93 \mathrm{Kgs}$ than by using steel. For less weight of the spring mechanical efficiency will be increased. By observing the structural analysis result, using Aramid Fiber is better than Glass Fiber since the stresses are less. But if we consider Frequency analysis, using Glass fiber is better since the frequencies are less, thereby reducing the vibrations. Structural and modal analysis are also conducted on the master leaf for single, 3 layers and 5 layers, 11 layers, 23 layers. From the results observed, if number of layers is increased for same thickness the vibrations are less. By reducing the vibrations, increase component life can be increased because more number of vibrations will cause sudden failure of springs because springs are like simply supported beam. In this project it can be concluded that using composite Aramid Fiber is advantageous since the weight and the stresses are less the major disadvantages of composite leaf spring are the matrix material has low chipping resistance when it is subjected to poor road environments which may break some fibers in the lower portion of the spring. This may result in a loss of capability to share flexural stiffness. But this depends on the condition of the road. In normal road condition, this type of problem will not be there. Composite leaf springs made of polymer matrix composites have high strength retention on ageing at severe environments. The steel leaf spring width is kept constant and variation of natural frequency with leaf thickness, span, camber and numbers of leaves are studied. It is observed from the present work that the natural frequency increases with increase of camber and almost constant with number of leaves, but natural frequency decreases with increase of span. The natural frequencies of various parametric combinations are compared with the excitation frequency for different road irregularities. The values of natural frequencies and excitation frequencies are the same for both the springs as the geometric parameters of the spring are almost same except for number of leaves.

\subsection{Future Scope}

By this project result, in future we can use composite material by replacing steel material. But

Experimental works like bending, torsion, hardness have to be done.

\section{References}

[1]. MARK'S Calculations for mechanical design by Thomas H. Brown

[2]. Machine Design by R.S. KHURMI, J.K. GUPTA

[3]. Mechanical Engineering Design by Budynas-Nisbett.

[4]. Mechanics of Solids by T.J.Prabhu.

[5]. Fundamentals of Materials Science and Engineering by William D. Callister

[6]. www.google.com

[7]. AL-Qureshi, H. A. Automobile leaf springs from composite materials, Journal of Processing Technol., 2001.

[8]. K. Tanabe, T. Seino, Y. Kajio, Characteristics of Carbon/Glass Fiber Reinforced Plastic Leaf Spring, 1982

[9]. Daugherty, R. L. Composite Leaf Springs in Heavy Truck Applications. K. Kawata, T.Akasaka (Eds). Composite Materials Proceedings of Japan-US Conference Tokyo,1981

[10]. R. M. Jones, Mechanics of Composite Materials. 2e, McGraw-Hill Book Company, 1990. 